\title{
O PLANEJAMENTO DAS OFICINAS DE LETRAMENTOS PARA O CONTEXTO ESCOLAR KALUNGA
}

\author{
THE PLANNING OF LITERACY WORKSHOPS FOR THE KALUNGA SCHOOL \\ CONTEXT
}

\author{
Roberta Rocha Ribeiro ${ }^{1}$
}

\begin{abstract}
Resumo: O presente artigo trata do planejamento das oficinas de Letramentos para estudantes da Escola Santo Antônio, situada na comunidade quilombola/Kalunga Vão de Almas-GO considerando a Licenciatura em Educação do Campo (LEdoC), da Universidade de Brasília (UnB), como locus formativo e como ponto de partida das ações pretendidas. Tal recorte faz parte da tese de Ribeiro (2017) e teve como objetivo principal iniciar a organização de ações cujo mote é contribuir socialmente com a referida comunidade no decorrer de produção da tese. O planejamento das oficinas de Letramentos mostra que as/os Kalunga envolvidas/os participaram de forma ativa, com protagonismo e comprometimento. Nesse sentido, este trabalho encontra-se estruturado em seções as quais apresentam as contextualizações, as concepções adotadas sobre Letramentos e escopos metodológicos; os registros e as reflexões do planejamento; e as considerações finais a respeito da temática desenvolvida.
\end{abstract}

Palavras-chave: Planejamento; oficinas de letramentos; comunidade Kalunga.

Abstract: This paper presents the planning of literacy workshops for students of The Santo Antônio School, located in the quilombola/Kalunga Vão de Almas-GO community considering the Undergraduate course in Rural Education (LEdoC), at the University of Brasília (UnB), as a formative locus and as a starting point of the intended actions. This research is part of Ribeiro's thesis (2017) and the main objective was to start organizing actions whose motto is to contribute socially to that community during the production of the thesis. The planning of the Literacy workshops shows that the Kalunga participated actively, with protagonism and commitment. In this sense, this work is structured in sections which present the contextualizations, the conceptions adopted on Literacies and methodological scopes; planning records and reflections; and the final considerations on the developed theme.

Keywords: Planning; literacy workshops; Kalunga community.

\section{Considerações iniciais}

Este trabalho tem o objetivo de apresentar o planejamento das oficinas de Letramentos presentes na tese de doutorado de Ribeiro (2017), intitulada O português kalunga do Vão de Almas-GO: a transitividade em discursos sobre o parto revelando letramentos. As oficinas mencionadas foram desenvolvidas em interações na Escola Santo Antônio do Vão de AlmasGO [comunidade quilombola/Kalunga situada no Cerrado do nordeste goiano], ao lado das/os professoras/es Kalunga, que eram também alunas/os da Licenciatura em Educação do Campo da Faculdade UnB Planaltina (doravante LEdoC/FUP/UnB) e de uma convidada, líder da comunidade, para estudantes de nono ano. O tema das oficinas de Letramentos foi, enquanto eixo, o parto. Isso propiciou a contribuição social da tese por meio de atividades multidisciplinares, sempre envolvendo Letramentos escolares, como leitura e escrita, e os Letramentos como práticas sociais inerentes às vivências humanas.

\footnotetext{
${ }^{1}$ Universidade Federal de Goiás, Goiás, GO, Brasil.
} 
No recorte aqui selecionado, registrado e revisitado, tratamos do planejamento que deu início às oficinas de Letramentos e, consequentemente, à tese citada. Faz-se necessário destacar que as/os docentes-estudantes Kalunga participaram, junto com a pesquisadora ${ }^{2}$, de todas as ações das oficinas em questão. Esse aspecto mostra o protagonismo do povo Kalunga e a fulcral formação que a Licenciatura em Educação do Campo promove à população quilombola/Kalunga e campesina do Cerrado, no Campus de Planaltina da Universidade de Brasília, há mais de uma década, contemplando as áreas de Linguagem, de Ciências e de Matemática. Logo, a LEdoC/FUP/UnB é nosso marco, é nosso ponto de partida para a elaboração de nossas intenções formativas.

Além disso, este estudo aponta para a relevância de pesquisadoras/es buscarem constructos plausíveis de contribuição social nas diversas áreas do conhecimento que suas teses, dissertações, projetos e congêneres possam abarcar. Para atingirmos nosso intuito, este artigo contém a seção Letramentos, na qual explicitamos o arcabouço teórico arrolado. Em seguida, tratamos do nosso modo de pensar/fazer pesquisa em Concepções metodológicas. Na sequência, explicitamos de maneira reflexiva o planejamento em si, na seção $O$ planejamento das oficinas de Letramentos: interações e expectativas de uma caminhada. Como fecho, no sentido de posicionamentos vivenciados, não de conclusões "únicas", tecemos percepções e comentários nas Considerações finais.

\section{Letramentos}

Neste estudo, adotamos os Letramentos como práticas sociais propostos por Street (2012, 2014). Também consideramos a vertente ecológica de Barton (1994) e o Letramento crítico de Luke (2000). De maneira geral, notamos que essas abordagens possuem como pontos de intersecção uma cosmovisão crítica e de cunho emancipatória: os Letramentos ultrapassam os muros da escola, não são atrelados apenas ao ato de alfabetizar e estão presentes nas ações/práticas sociais multifacetadas de uma dada sociedade. Portanto, os Letramentos são as leituras e escritas subjetivas, sensíveis, práticas, sociais e históricas da escola e da vida considerando a escola ligada à vida, não um ambiente isolado.

Assim, esse escopo contribui na percepção de que saberes tradicionais, vivenciados, ensinados de geração em geração, não podem ser desconsiderados em prol de uma visão hegemônica dos cânones ocidentais. Logo, associar o conhecimento do povo Kalunga acerca do parto e de suas imbricações com atividades de Letramentos no bojo escolar (sendo a escola uma instituição de grande valor para a sociedade Kalunga) é, sim, um arquétipo social e pedagógico válido e relevante; é uma forma de aproximação dos Letramentos escolares com a vida pulsante de uma comunidade constituída de gente e de sua historicidade.

Tais concepções são importantes para contribuir na legitimação e no reconhecimento dos Letramentos na sociedade Kalunga como um todo. Por exemplo: quando uma mulher mais velha ensina para uma jovem os cuidados necessários para uma gestação, um parto, um pósparto, isso constitui Letramentos. Estes são saberes de práticas sociais situadas, passados de geração em geração. Nesse sentido, a menção e, principalmente, a discussão sobre esses Letramentos orais em suas predominâncias buscam alcançar a ideia de registro e legitimação. Por isso, como contribuição social, em Ribeiro (2017) há o desenvolvimento das oficinas de Letramentos as quais ligaram realidade social e realidade escolar. Isso pelo motivo da escola ser parte da realidade social, porém, muitas vezes, acaba sendo segregada devido à ausência dessas interfaces propiciadas pelos Letramentos. Essas concepções mostram a relevância de considerarmos os conhecimentos, especialmente das/os Kalunga do Vão de Almas-GO, como

\footnotetext{
${ }^{2}$ Enquanto pesquisadora, nesse tempo de produção de tese de doutorado pelo Programa de Pós-Graduação em Linguística da UnB, também atuei como docente-colaboradora da área de Linguagem da LEdoC/FUP/UnB.
} 
saberes típicos do Cerrado e em uma posição contra-hegemônica no processo de desenvolvimento de leitura e escrita, em contexto escolar, da referida comunidade.

\section{Concepções metodológicas}

A partir dos referenciais teóricos adotados neste estudo, nossa metodologia está calcada na postura ecoetnográfica (RIBEIRO, 2017; COUTO, 2007; SOUSA, 2006; THOMAS, 1999), na pesquisa qualitativa (BORTONI-RICARDO, 2008; ALAMI; DESJEUX; GARABUAUMOUSSAOUI, 2010), com movimentos da pesquisa-ação (TRIPP, 2005; BARBIER, 2007; THIOLLENT, 2011). Em outras palavras, as vivências da pesquisa partiram da colaboração e imersão no ambiente ecolinguístico das/os colaboradoras/es. É por esse motivo que nossa pesquisa é de postura ecoetnográfica: observação, geração, análise e colaboração foram realizadas com as/os Kalunga (povo), via língua (Português Kalunga, como variante do Português Brasileiro) no território Vão de Almas-GO e nas interações com estudantes Kalunga pertencentes à LEdoC/FUP/UnB, em encontros na cidade de Brasília-DF, com a convivência, por imersão, entre pesquisadora e colaboradoras/es dessa/nessa sociedade do Cerrado. Essas concepções foram fundamentais para a construção de um trabalho que valoriza a interação, o protagonismo e a escuta das vozes Kalunga no planejamento das oficinas de Letramentos pretendidas.

\section{O planejamento das oficinas de Letramentos: interações e expectativas de uma caminhada}

As oficinas de Letramentos para o nono ano da Escola Santo Antônio, na comunidade Kalunga Vão de Almas-GO, constam no trabalho de tese de Ribeiro (2017) a partir do eixo dos Letramentos pelo seguinte motivo: com o objetivo de deixar uma contribuição social na escola da comunidade por meio das oficinas. Tais atividades foram solicitadas pelas/os licenciandas/os Kalunga em Educação do Campo da UnB, pois, ao mesmo tempo em que estavam na formação inicial docente, muitas/os já atuavam como professoras/es da escola em tela. Ademais, esse pedido demonstra o cansaço do povo Kalunga em ser mero objeto de pesquisa para observação e reflexão de outrem; o povo Kalunga anseia, com toda a razão, participar ativamente, assumir o protagonismo e colher contribuições sociais de questões as quais permeiam sua trajetória de vida. Enquanto pesquisadora e ser humano, a partir da escuta sensível de Barbier (2007), escutei, ouvi, compreendi, refleti e busquei incessantemente atender uma demanda tão legítima. Por isso, o planejamento das oficinas não é somente uma etapa didática a ser cumprida. Ele alcança a simbologia do "abre-alas" de uma jornada de inerência humana e social.

Nesse sentido, vale ressaltar que realizamos três rodadas de oficinas. A primeira, em maio de 2015, teve duração de três dias envolvendo estudantes do nono ano, docentes Kalunga, D. $\mathrm{D}^{3}$. e pesquisadora. A segunda, por sua vez, em junho de 2015, contou com a participação das/os discentes do nono ano, das/os professoras/es Kalunga e pesquisadora. A última etapa aconteceu em julho de 2015 com a participação apenas das/os docentes Kalunga e da pesquisadora. Todas as rodadas ocorreram após aprovação da pesquisa de Ribeiro (2017) pelo Comitê de Ética em Ciências Humanas da UnB.

Nós, licenciandas/os-docentes Kalunga da Escola Santo Antônio e pesquisadora, elaboramos as oficinas de modo multidisciplinar e partindo dos conhecimentos típicos e orais Kalunga, nos momentos de estudo do calendário da LEdoC/FUP/UnB em Brasília-DF, antes da ida da pesquisadora até o Vão de Almas-GO, pautado na Alternância. Em breves palavras, de acordo com

\footnotetext{
${ }^{3}$ D. D. é uma das lideranças da comunidade que, gentilmente, aceitou nosso convite para participar das oficinas e que, por questões éticas de pesquisa, preservamos sua identidade. $\mathrm{O}$ mesmo procedimento ético foi adotado com todas/os colaboradoras/es deste estudo.
} 
Antunes-Rocha e Martins (2012), a Alternância consiste na articulação entre conhecimentos científicos e populares vivenciados na Universidade e nas comunidades de origem das/os discentes. Nesse contexto, registramos aqui nosso planejamento que demonstra interações e expectativas no tocante às oficinas para a Escola Santo Antônio do Vão de Almas-GO.

Em primeiro lugar, participaram dos encontros de elaboração da oficina sete docentes Kalunga. Entre elas/es, três eram professoras/es contratadas/os e as/os demais estavam cumprindo as atividades de estágio docente da LEdoC/FUP/UnB na Escola Santo Antônio. O primeiro encontro ocorreu com o intuito de apresentar a proposta da temática "parto" para as oficinas, visto que o trabalho de tese tem como mote a análise da transitividade do discurso do parto de mulheres Kalunga do Vão de Almas-GO. E havia a necessidade de alinhavar as propostas das oficinas e da tese como um todo. Como pesquisadora, relatei que seria possível e interessante trabalhar com o nono ano pela maturidade em relação ao tema e falei sobre meu projeto de tese. As/os professoras/es Kalunga explicitaram bastante interesse em participar com essa temática, e cada um/a expressou sua opinião e suas expectativas. De forma geral, elas/es apontaram que o parto é uma questão crucial na comunidade devido ao conhecimento próprio ligado aos saberes das mulheres, parteiras e homens de uma comunidade quilombola, campesina, bem como, nos dias atuais, a busca e realização de partos em hospitais considerando o fato do Vão de Almas-GO ser de difícil acesso no quesito estradas e transportes. $\mathrm{O}$ ir e vir em estradas de terra com serras não é uma tarefa simples, tampouco com qualquer carro. É necessário o uso de veículos traçados.

Após esse primeiro momento de articulação temática, a indagação de como ensinar em uma abordagem multidisciplinar, como a LEdoC/FUP/UnB orienta em seu bojo epistemológico e pedagógico, foi a grande tônica dessa conversa inicial. Diante disso, na posição de pesquisadora, provoquei algumas reflexões, por escrito, acerca da pergunta "Que professor/a desejo ser?". Essa reflexão motivou as/os professoras/es a reservar um tempo de estudo para, por meio da oficina, cada um/a buscar a melhoria e, em essência, o(s) sentido(s) de suas práticas pedagógicas. No encontro subsequente, discutimos o plano de aula. Elas/es queriam aprender a fazer plano de aula, pois relataram muitas dificuldades nessa atividade. Nesse instante, foi apresentado o seguinte modelo de plano:

\begin{tabular}{|c|c|c|c|c|}
\hline $\begin{array}{l}\text { Escola Est } \\
\text { Vão de Aln } \\
\text { Tema das a } \\
\text { Série: } \\
\text { Turma: } \\
\text { Disciplina: } \\
\text { Data: }\end{array}$ & $\begin{array}{l}\text { Calunga } \mathbf{4}^{\mathbf{I}} \\
\text { O Professor }\end{array}$ & nsão Escola S & o Antônio & \\
\hline Objetivos & Conteúdos & Metodologia & Avaliação & Recursos \\
\hline
\end{tabular}

Quadro 1 - Modelo de Plano de Aula desenvolvido com as/os professoras/es Kalunga (RIBEIRO, 2017, p. 104)

Utilizamos esse modelo sintético pela dificuldade de se fazer um plano de aula relatada pelas/os estudantes-docentes Kalunga. Nessa época, elas/es ainda estavam em reflexão sobre como a direção da escola e o estágio na Universidade solicitavam o plano. Desse modo, tal modelo funcionou como uma ferramenta introdutória, prática, com os elementos fundamentais

\footnotetext{
${ }^{4}$ A grafia do nome da escola, em documentos oficiais do Estado de Goiás, contém a palavra "Calunga" iniciada com a letra "c", não "k". Contudo, a comunidade é nomeada com a letra inicial "k" (Kalunga).
} 
de um plano de aula para que as/os licenciandas/os sanassem suas dúvidas iniciais relacionadas ao fazer um plano de aula. Todas/os receberam uma cópia desse modelo de plano e, depois da apresentação, como pesquisadora, expliquei cada uma das partes do plano de aula e começamos a discutir qual seria o tema geral das aulas.

Com muito diálogo, chegamos ao seguinte tema transversal: "os cuidados típicos Kalunga antes e depois do parto (abordagem multidisciplinar)". Eu, como pesquisadora, reproduzi no quadro o plano e fui preenchendo os campos junto com as/os estudantes-docentes Kalunga, no instante em que chegávamos a um consenso sobre determinada parte do plano. Quanto às datas das aulas, decidimos que duas tardes seriam mais relacionadas às disciplinas de Ciências e Matemática e duas de Língua Portuguesa, sendo realizadas conforme agendamento de ida da pesquisadora. E, sempre em momento posterior às aulas, teríamos uma interação dedicada à autoavaliação da oficina. A autoavaliação foi vista como instrumento pedagógico de pensamento crítico a respeito de nossas ações e anseios, incluindo todas/os as/os envolvidas/os no processo. Nessa seara de intensa interlocução, os objetivos floresceram e foram elencados da seguinte maneira:

\section{Ciências e Matemática:}

- melhorar os conhecimentos sobre as quatro operações matemáticas;

- inserir os conhecimentos relacionados à medição de temperaturas;

- conhecimento das plantas Kalunga para produção dos remédios tradicionais.

\section{Língua Portuguesa:}

- discussão da temática parto e seus cuidados partindo dos conhecimentos orais do povo Kalunga;

- registrar os conhecimentos sobre as plantas medicinais do território Kalunga Vão de Almas-GO;

- articular os conhecimentos supracitados com atividades de leitura e escrita à luz dos gêneros textuais receita e relato.

Quadro 2 - Propostas de objetivos das Oficinas de Letramentos (RIBEIRO, 2017, p. 105)

Nessa etapa, as/os estudantes-docentes Kalunga estavam ainda mais dependentes das orientações da pesquisadora; elas/es ainda não tinham compreendido plenamente o que são os objetivos. Mas, na escolha dos conteúdos, elas/es avançaram bastante e assumiram, de fato, o protagonismo. Ficou nítido que os objetivos delas/es eram, com a contribuição social das oficinas de Letramentos solicitadas, melhorar leitura, escrita e conhecimentos básicos de Matemática e Ciências das/os alunas/os do nono ano. Os professores de Ciências e de Matemática relataram que as/os discentes de nono ano têm dificuldades com as quatro operações, e não conseguem entender a medição em graus, por exemplo. Eles também sugeriram ensinar dosagem de remédios. Assim, os conteúdos foram decididos coletivamente:

\section{Ciências e Matemática:}

- as quatro operações;

- conhecimento das ervas Kalunga relacionadas ao parto;

- produção de um remédio ou chá Kalunga;

- uso de termômetro e medição de graus.

Quadro 3 - Propostas de conteúdos de Ciências e Matemática para as oficinas de Letramentos (RIBEIRO, 2017, p. 105) 
As/os docentes em questão, no tocante aos gêneros textuais, se manifestaram a favor do trabalho com o gênero receita. Elas/es mencionaram a dificuldade de se trabalhar os conteúdos de Língua Portuguesa, na escola, na perspectiva dos gêneros textuais. Por isso e pelo tema geral das oficinas, as/os docentes pediram que trabalhássemos juntas/os o gênero textual receita.

\section{Língua Portuguesa:}

- discussão em sala de aula sobre a temática parto e cuidados Kalunga com o intuito de motivar reflexões e, depois, esse momento servir de apoio na produção de receitas;

- leitura e interpretação coletiva de uma receita para que as/os estudantes do nono ano conheçam o gênero;

- produção do gênero receita e os conhecimentos dos remédios da comunidade.

Quadro 4 - Propostas de conteúdos de Língua Portuguesa para as oficinas de Letramentos (RIBEIRO, 2017, p. 106)

Quanto à metodologia, o nosso planejamento ficou da seguinte forma:

Primeiro dia: os professores de Ciências e Matemática, juntos, discutirão com as/os estudantes de nono ano a importância de saber a respeito das ervas típicas do território Kalunga, do quanto elas podem ser úteis para a saúde de uma gestante e de uma mulher que acabou de ter filha/o e para a saúde do povo Kalunga de modo geral.

Segundo dia: a convite das/dos professoras/es, D. D., senhora e uma das líderes da comunidade, irá até a escola ensinar ao alunado de nono ano a fazer um chá relacionado aos cuidados da mulher gestante e do parto. E, nesse instante, a cada explicação de D D, os professores de Matemática ensinarão a registrar a dosagem por meio das quatro operações. E, no momento de ferver/esfriar o chá, os professores de Ciências ensinarão a medir o grau por meio de um termômetro. Ao final, os docentes solicitarão atividades relacionadas a esse momento construídas por eles mesmos.

Terceiro dia: Os professores de Ciências e Matemática discutirão em classe a atividade solicitada. Depois, duas professoras de Língua Portuguesa utilizarão o contexto vivenciado no dia anterior para introduzir o gênero receita. Na segunda parte da aula, uma professora ensinará as características básicas do gênero receita e vai propor a escrita, em caráter introdutório, de alguma receita de remédio tradicional que auxilia gestantes ou no pós-parto. Essas receitas serão transcritas em cartolinas.

Quarto dia: Duas professoras de Língua Portuguesa utilizarão os conhecimentos discutidos para desenvolverem escrita individual e coletiva do gênero receita, tendo como tema os ensinamentos de D. D., realizando interfaces com os conteúdos de Ciências e Matemática. Haverá também o instante de reescrita, para melhoria da escrita, conforme orientação em sala.

Quinto dia: A pesquisadora e uma das professoras trabalharão o gênero relato sobre a temática em tela com o objetivo de melhorar leitura e produção escrita do alunado. Ao final, as/os professoras/es e a pesquisadora conversarão com as/os discentes para fazer a autoavaliação das oficinas. Obs.: sempre depois de todas as etapas, as/os professoras/es e a pesquisadora se autoavaliarão.

Quadro 5 - Planejamento das aulas da Oficina de Letramentos (RIBEIRO, 2017, p. 106) 
A avaliação das/os alunas/os ocorreu em todo o processo, com as produções escritas e orais desenvolvidas nas oficinas. Os recursos foram quadro, giz, caderno, lápis, folhas brancas/coloridas, cartolinas, lápis de cor, termômetro e ervas da comunidade para a produção do chá ensinado por D. D. E, certamente, podemos falar também em recurso humano: as ideias e iniciativas das/os professoras/es Kalunga, de D. D., do corpo discente Kalunga e da pesquisadora. Dessa forma, nosso planejamento foi concluído para que nossa caminhada pudesse ser vivenciada.

\section{Considerações finais}

Esse primeiro planejamento serviu para colocar em prática, com as/os professoras/es Kalunga, um princípio que aprendemos quando estudamos os Letramentos: não existe um caminho pronto para o processo de ensino-aprendizagem. Cada realidade deve ser observada, e os Letramentos no âmbito da escola devem estar, sim, em consonância com os Letramentos orais, socializados pela comunidade. Esse viés foi fundamental para a contribuição social que fizemos junto com a comunidade Kalunga no contexto escolar. Outro ponto é que todo o material escrito das/os estudantes de nono ano e as aulas foram gravados e arquivados pela pesquisadora, mediante autorização dos pais. E esse material serviu de registro e comprovações da contribuição social descrita e experienciada na tese de Ribeiro (2017).

Vale ressaltar que, metodologicamente, as oficinas também funcionaram como ponto de aproximação ética entre pesquisadora e comunidade; a pesquisadora fez, em campo, durante o processo de produção da sua tese, as parcerias solicitadas pelas/os Kalunga no ambiente da escola. Acreditamos que estudos, pesquisas e trabalhos os quais abordem comunidades minoritárias, como a comunidade quilombola/Kalunga Vão de Almas-GO, precisam propiciar uma devolutiva às pessoas envolvidas. Tal devolutiva não é um pagamento ou algo similar. É deixar um pouco de si com a comunidade, sempre com muito respeito e conforme as especificidades/necessidades existentes e apresentadas pelas/os colaboradoras/es.

\section{Referências}

ALAMI, S.; DESJEUX, D.; GARABUAU-MOUSSAOUI, I. Os métodos qualitativos. Tradução de Luis Alberto S. Peretti. Petrópolis, RJ: Vozes, 2010.

ANTUNES-ROCHA, M. I.; MARTINS, M. de. F. A. Tempo Escola e Tempo Comunidade: Territórios Educativos na Educação do Campo. In: ANTUNES-ROCHA, M. I.; MARTINS, M. de. F. A.; MARTINS, A. A. (Org.). Territórios educativos na Educação do Campo: escola, comunidade e movimentos sociais. Belo Horizonte: Autêntica, 2012. p. 21-33.

BARBIER, R. A Pesquisa-Ação. Tradução de Lucie Didio. Brasília: Liber Livro Editora, 2007.

BARTON, D. Literacy: an introduction to the Ecology of Written Language. Oxford UK \& Cambridge USA: Blackwell, 1994.

BORTONI-RICARDO, S. M. O professor pesquisador: introdução à pesquisa qualitativa. São Paulo: Parábola Editorial, 2008.

COUTO, H. H. do. Ecolinguística: estudo das relações entre língua e meio ambiente. Brasília: Thesaurus, 2007. 
LUKE, A. Critical Literacy in Australia. Journal of Adolescent and Adult Literacy, USA, v. 43, 2000. Disponível em: http://www.paddle.usp.ac.fj/collect/paddle/index/assoc/pride024.dir/doc.pdf. Acesso em: 20 out. 2020.

RIBEIRO, R. R. O português kalunga do Vão de Almas-GO: a transitividade em discursos sobre o parto revelando letramentos. 2017. Tese (Doutorado em Linguística) - Programa de Pós-Graduação em Linguística, Universidade de Brasília, Brasília, 2017.

SOUSA, R. M. de. Gênero Discursivo Mediacional, da Elaboração à Recepção: uma Pesquisa na Perspectiva Etnográfica. 2006. Tese (Doutorado em Linguística) - Programa de PósGraduação em Linguística, Universidade de Brasília, Brasília, 2006.

STREET, B. Eventos de letramento e práticas de letramento: teoria e prática nos Novos Estudos do Letramento. In: MAGALHÃES, I. (Org.). Discursos e práticas de letramento: pesquisa etnográfica e formação de professores. Tradução de Izabel Magalhães. Campinas, SP: Mercado de Letras, 2012. p. 69-92.

STREET, B. Letramentos sociais: abordagens críticas do letramento no desenvolvimento, na etnografia e na educação. Tradução de Marcos Bagno. São Paulo: Parábola Editorial, 2014.

THIOLLENT, M. Metodologia da pesquisa-ação. São Paulo: Cortez, 2011.

THOMAS, J. Doing critical ethnography. London: SAGE, 1999.

TRIPP, D. Pesquisa-ação: uma introdução metodológica. Tradução de Lólio Lourenço de Oliveira. Educação e Pesquisa, São Paulo, v. 31, n. 3, set.-dez. 2005. Disponível em: http://www.scielo.br/pdf/ep/v31n3/a09v31n3.pdf. Acesso em: 20 out. 2020.

\section{Sobre a autora}

Roberta Rocha Ribeiro é bacharela em Letras - Língua Portuguesa e Linguística pela Universidade Federal de Goiás (2005), licenciada em Língua Portuguesa e Literaturas Correspondentes pela Universidade Católica de Goiás/PUC Goiás (2007), mestra em Letras e Linguística pela Universidade Federal de Goiás (2009) e doutora em Linguística pela UnB (2017). Atualmente, é Professora Adjunta da Licenciatura em Educação do Campo da Universidade Federal de Goiás/Regional Goiás, vice-líder do Grupo de Pesquisa (Socio)Linguística, Letramentos Múltiplos e Educação (SOLEDUC) e integrante do Grupo de Estudos e Pesquisas em Linguística Ecossistêmica (GEPLE) - ambos certificados pelo CNPq. E-mail: letras.roberta@gmail.com. 